\title{
VulNERABILIDAD SUICIDA EN LOCALIDADES RURALES DE CHIAPAS: UNA APROXIMACIÓN ETNOGRÁFICA
}

\author{
Suicide Vulnerability in Rural Localities in Chiapas: an Ethnographical Approach
}

\author{
Gracia Imberton-Deneke
}

\begin{abstract}
Resumen: Si bien el suicidio es un fenómeno apremiante por el incremento que ha experimentado a nivel mundial y nacional, los estudios sociales sobre este tópico son escasos. Es imprescindible realizar más investigaciones sobre el tema, así como reflexionar y discutir perspectivas analíticas viables. En este artículo examino la dimensión social de la muerte autoinflingida en las localidades Río Grande y Cantioc del estado de Chiapas, México, y propongo una aproximación etnográfica para su análisis. Consciente de las dificultades metodológicas que entraña la construcción tanto de los datos empíricos del suicidio como de sus explicaciones causales, planteo que un acercamiento al contexto histórico del espacio social en cuestión y a las condiciones de vida actuales de la población permite derivar algunas correlaciones entre posiciones sociales, tensiones y conflictos, $y$ vulnerabilidad suicida.
\end{abstract}

Palabras clave: suicidio, enfoque etnográfico, dificultades metodológicas, posiciones sociales, vulnerabilidad.

Abstract: While suicide is a compelling phenomenon that has experienced substantial growth on a global and national scale, social studies on this topic are scarce. It is imperative to conduct more research on the subject, and to reflect and discuss viable analytical perspectives. In this article, I examine the social dimension of self-inflicted death in Río Grande and Cantioc in Chiapas, Mexico, through an ethnographical approach. Aware of the methodological difficulties involved in the construction of suicide data and the local causal explanations, I argue that an approach to both the historical context of a particular social space and the current living conditions of the population enables us to draw some correlations between social positions, tensions and conflicts, and suicide vulnerability.

Keywords: suicide, ethnographical approach, methodological difficulties, social positions, vulnerability.

Gracia Imberton Deneke, doctora en estudios mesoamericanos por la Universidad Nacional Autónoma de México. Profesora-investigadora en el Instituto de Estudios Indígenas de la Universidad Autónoma de Chiapas, México. Temas de especialización: suicidio, conflictos sociales, enfermedad. Correo electrónico: gimberton@gmail.com.

Enviado a dictamen: 13 de diciembre de 2013.

Aprobación: 22 de febrero de 2014.

Revisiones: 1 . 


\section{Acercamiento etnográfico al estudio del suicidio}

L os índices de suicidio han experimentado un incremento alarmante tanto a nivel mundial como nacional. Basta revisar rápidamente las cifras que proporcionan las distintas instituciones que los registran para captar la magnitud del fenómeno (OMS, 2012; INEGI, 2013). Sin embargo, las investigaciones sobre esta problemática en general son escasas e insuficientes. Hay pocos estudios sociales y antropológicos, y menos aún referidos al medio rural. Para el caso de América Latina, Arias y Blanco (2010) analizan este desinterés en su sugerente artículo "Una aproximación al entendimiento del suicidio en comunidades rurales y remotas de América Latina”. Según estos investigadores, tanto los académicos como la población latinoamericana en general comparten una "representación idílica de lo rural" que ha contribuido a invisibilizar el suicidio en ese medio. Esta visión encierra una concepción particular de las sociedades rurales, a las que se caracteriza como entes armónicos que favorecen el interés colectivo por encima del individual y que mantienen relaciones de solidaridad mecánica (Emile Durkheim) o de tipo gemeinschaft o comunidad (Aldous, Durkheim y Tönnies, 1972).

En el caso de México, la antropología contribuyó durante décadas a reproducir la idealización de lo rural, principalmente en las sociedades indígenas. Los antropólogos abrevaron del trabajo de Tönnies y describieron la sociedad rural mexicana en términos de la comunidad tönniesiana: armónica, igualitaria, homogénea económicamente, fundada en el consenso en torno a la religión y la tradición, y con una forma de organización social basada en el parentesco (Viqueira, 1995; Lisbona, 2005). En esta visión, los conflictos internos generalmente no tienen cabida y el cambio social se reconoce principalmente como un elemento desintegrador negativo.

Otras cuestiones metodológicas han influido también en la desatención al suicidio. Podría pensarse que el acercamiento etnográfico presenta enormes ventajas para profundizar en temas tan delicados como éste, en la medida en que el investigador establece una relación empática de largo plazo con sus informantes (Jones, et al. 2007: 463). Sin embargo, se argumenta que los índices de suicidio en general son muy bajos y por tanto el investigador difícilmente podrá encontrar regularidades en los plazos finitos de la investigación de campo (Johnson, 1981: 325). También se menciona que el carácter íntimo y no anticipado del suicidio hace imposible observar sus antecedentes o el hecho mismo (Owens y Lambert, 2012). Romanucci-Ross destaca además la limitante metodológica de que no se puede entrevistar a la víctima (citada en Owens and Lambert, 2012). Chua (2009), por su parte, ha expuesto otro tipo de motivos. Ella plantea que el desinterés o rechazo de los antropólogos al tema quizá reside en que el suicidio es visto sólo como un acto de destrucción, contrario a los temas que tradicionalmente investiga esta disciplina: cultura, parentesco y vida social.

Entre las consideraciones metodológicas, destaca una muy importante. Paul Bohannan, coordinador del volumen African Homicide and Suicide de 1967, una de las primeras obras antropológicas que trata el tema, plantea las dificultades que supone explicar la causalidad suicida. El autor discute las afirmaciones de Emile Durkheim (1998), quien señala que las verdaderas causas del suicidio se encuentran en aspectos estructurales de la sociedad, de los que la víctima puede no estar consciente. Por esta razón, Durkheim desestima un acercamiento etnográfico ya que considera inoperante conocer siquiera las causas individuales que pudieran ofrecer las personas cercanas a la víctima o estas mismas en sus cartas de despedida. Bohannan (1967) acepta la explicación estructural durkheimiana, pero distingue, en cambio, dos definiciones de motivo: una la refiere a la "etiología síquica", que considera imposible conocer pues - agrega el autor - nadie puede saber realmente lo que empujó a la víctima a suicidarse; y la otra es la explicación folk, es decir, la causa que los sobrevivientes le atribuyen al hecho. Bohannan indica que este último motivo - la explicación folk- es pertinente para un acercamiento etnográfico porque, aunque no sea necesariamente la causa directa del 
suicidio, muestra las ideas populares en torno a lo que significa para el grupo en cuestión "aquello por lo que vale la pena vivir o morir" (1967: 26). Owens y Lambert (2012) apuestan también por un acercamiento etnográfico, y destacan igualmente que el estudio de los casos es inevitablemente retrospectivo; más que analizar el acto de quitarse la vida, dicen las autoras, la etnografía debe examinar las formas en que dicho acto es interpretado y explicado en el medio social donde ocurrió.

Coincido con Bohannan, Owens y Lambert en la necesidad de impulsar investigaciones antropológicas sobre suicidio que nos permitan conocer las "explicaciones folk", consciente de que éstas son construidas a posteriori y pueden realizarse con el propósito -intencional o no- de culpabilizar, acusar o evadir responsabilidad del hecho, lo que impone mayor precaución metodológica. Discrepo, por tanto, del planteamiento de Durkheim que, al reconocer únicamente causas estructurales, omite adentrarse en el contexto particular en que se presenta el suicidio.

Además de indagar en torno a las explicaciones causales locales —algo que aquí retomo sólo parcialmente-, propongo que un acercamiento antropológico al suicidio debe contemplar el análisis de la dimensión social. Como ha señalado Chua en su interesante investigación sobre la India, para analizar el suicidio en determinado lugar y época hay que atender a "la conjunción particular de las condiciones históricas, sociales y culturales en las que la violencia en contra del cuerpo puede acumular valor social, económico y político dentro de contextos transaccionales situados" (2009: 17, traducción propia). El objetivo de este artículo es entonces describir las tensiones y conflictos locales que son asociados causalmente al suicidio, examinar la dinámica de poder del espacio social que subyace a estas fricciones - las desigualdades de género, edad, parentesco y condición socioeconómica principalmente-, y establecer la vulnerabilidad de los diferentes grupos o posiciones sociales en relación con sus expectativas y aspiraciones, todo esto enmarcado en el contexto más amplio de los cambios sociales globales y locales-. ${ }^{2}$

\section{Las cifras de suicidio}

Aunque mi objetivo era realizar una investigación cualitativa sobre el suicidio, consideré indispensable conocer, en la medida de lo posible, los datos básicos de las víctimas, así como aproximarme a los índices de este fenómeno en las dos localidades de estudio, Cantioc y Río Grande, del municipio de Tila, Chiapas. En este apartado doy cuenta de la información obtenida, con resultados francamente alarmantes, pero también aprovecho para destacar algunas de las dificultades que supone la construcción de los datos sobre suicidio.

Las estadísticas oficiales de suicidio han sido motivo de discusión y controversia desde que se publicó el libro de Durkheim El suicidio, en 1897. ${ }^{3}$ Un cuestionamiento importante pone en tela de juicio si los registros oficiales ofrecen una cobertura completa y si la información es confiable. Para esta investigación consulté diversas fuentes oficiales a la vez que realicé conteos etnográficos - uno por cada localidad-. Revisé los archivos del Registro Civil en Tila y Petalcingo, del Juzgado Municipal de Tila y del Hospital Regional de Tila. También obtuve alguna información en la "clínica" o Unidad Médica Rural del Instituto Mexicano del Seguro Social (IMSS-Oportunidades) de Cantioc. No conseguí autorización, sin embargo, para revisar las fichas de "intento de suicidio o suicidio" que debe llenar el Ministerio Público y que centraliza posteriormente el Instituto Nacional de Geografía y Estadística (INEGI) para su tabulación estadística. Tanto el Ministerio Público de Yajalón, al que corresponde la región de estudio, como la oficina de INEGI en Tuxtla Gutiérrez, afirmaron que este material es confidencial. Dicha ficha contiene datos relevantes que no se encuentran en los registros de las otras instituciones. ${ }^{4}$

De los archivos consultados, el Registro Civil ofrece la mayor cantidad de información en comparación con los otros y se encuentra sistematizada por años. ${ }^{5}$ Por estas razones retomé principalmente la información de las actas de defunción del Registro Civil, que incluyen datos generales de la víctima y el suceso: fecha y lugar de nacimiento, sexo, fecha del suicidio, y otros registrados muy irregularmente, como escolaridad, religión y estado 
civil, además de un breve apartado para describir el método de muerte. El diagnóstico aparece muchas veces confirmado por un médico que firma al calce. ${ }^{6}$

Al obtener los primeros resultados, destacaron las diferencias entre la información de campo y la proveniente de fuentes oficiales, pues el acercamiento etnográfico me permitió identificar más casos de suicidio que los incluidos en el Registro Civil — sin pretender que los conteos que realicé sean completos y definitivos-. Esta situación tiene varias explicaciones. Por un lado, el trabajo que realiza el Registro Civil presenta deficiencias a nivel nacional en la cobertura de las zonas rurales, especialmente las más aisladas. Por otro lado, los familiares de la víctima buscan evitar los largos y costosos trámites oficiales que implica la muerte por suicidio. La legislación mexicana exige abrir un proceso judicial por homicidio hasta que se demuestre, con testigos y evidencia, que la muerte fue decisión de la víctima. Los familiares deberán abandonar sus localidades y trabajos, desplazarse hasta Yajalón varias veces - costeando sus gastos así como los de dos testigos que deben acompañarlos-, y enfrentarse a la burocracia que dilata y complica los procedimientos sin más. ${ }^{7}$ Según algunos entrevistados, en ocasiones han sido las autoridades encargadas del levantamiento de cadáveres quienes les han sugerido evitarse todas las molestias y declarar otro tipo de muerte cuyo registro no demande tanto tiempo, recursos económicos y esfuerzo.

También es frecuente que los pobladores oculten que el suicidio sea la causa de defunción y declaren - a las autoridades y al antropólogo —otras diferentes para encubrir el hecho, pues genera suspicacia entre la gente en torno a si la familia tenía problemas y no los atendió debidamente y a tiempo. Son muy frecuentes los chismes que se traducen en acusaciones por este motivo.

La elaboración de los conteos etnográficos no estuvo libre de dificultades. Consideré necesario establecer un recorte temporal puesto que había que depender de la memoria de la gente, así que delimité un periodo de veinte años, de 1985 a 2005. Con respecto a Río Grande fue relativamente sencillo pues eran pocos los suicidios — seis- Yo había desarrollado allí una investigación anteriormente, así que existía una relación de confianza e incluso había conocido a varias de las víctimas. En Cantioc, en cambio, la situación fue más complicada. Las cifras eran más altas, no había una relación previa con la gente del lugar, y además las casas están dispersas en un territorio amplio y escarpado, por lo que busqué el apoyo del auxiliar de salud y autoridades municipales. A partir de una primera lista de veintiún casos que ellos elaboraron, inicié la exploración.

Visité a todas las familias con víctimas de suicidio de las que tuve noticia - las consignadas en el Registro Civil y en el listado de las autoridades locales, así como las que me fueron referidas por otros pobladores-; solicité datos básicos como edad, género, método de suicidio, ocupación, escolaridad, estado civil y religión. A diferencia de las fuentes oficiales, el acercamiento etnográfico me permitió profundizar más en las explicaciones causales. En algunas ocasiones pude comentar un mismo caso con más de veinticinco personas allegadas a la víctima, y tuve oportunidad de volver a platicar con ellas varias veces más. Para otros casos sólo hablé con dos familiares en una única sesión. Por tanto, la información recopilada es desigual, en parte por cierta desconfianza acerca del manejo que podría hacerse de ella, pero también por el desconocimiento de la familia de los datos solicitados -incluso de la edad y fecha del suceso-.

De un total de cuarenta casos recogidos en campo, por ejemplo, sólo diecisiete estaban consignados como suicidio en las actas de defunción del Registro Civil. Del resto, muchos estaban registrados bajo otro tipo de muerte - vómito, fiebre, calambre, paro cardiorrespiratorio, anemia aguda, desnutrición, dolor de cabeza, calentura, síndrome febril, deshidratación, ataque epiléptico, ataque epiléptico que duró tres meses y derrame cerebral-, mientras que algunos no aparecieron como fallecidos.

Para el período de 1985 al 2005, registré 43 suicidios sumando las dos fuentes - Registro Civil y conteos etnográficos-: 37 en Cantioc y 6 en Río Grande. A continuación expongo los datos sobre género, edad y estado civil de las víctimas de suicidio. Sobre el género del suicida, la relación hombre-mujer es semejante en ambas localidades y revela que son más los hombres que 
se quitan la vida que las mujeres: en Cantioc, veintitrés son hombres y catorce mujeres; en Río Grande, cuatro son hombres y, dos, mujeres.

Los datos sobre la edad de los suicidas revelan mayores diferencias entre ambas localidades. Para Cantioc, me referiré solamente a 35 casos - no fue posible confirmar la edad de dos víctimas-; 11 mujeres y 24 hombres. En esta localidad, las mujeres se encuentran distribuidas de manera más homogénea a lo largo de todo el espectro de edades: diez casos entre los 10 y 44 años, y un caso de persona mayor de 60 años. Entre los hombres, en contraste, es muy notorio que los suicidios se encuentran concentrados en dos grupos de edad principalmente: de 20 a 24 años hay siete casos - y si ampliamos este grupo para incluir a los de 15 a 19 así como a los de 25 a 29 años resultan doce suicidios-, y de 35 a 39 años hay seis casos - si agregamos el grupo de 40 a 44 serían nueve suicidios-. De los tres casos restantes, uno se ubica en el grupo de edad de 30 a 34, y los otros dos, de 55 años y más. Destaca el alto porcentaje de suicidios entre hombres jóvenes en edad productiva y reproductiva.

En la localidad de Río Grande, con menos casos de suicidio que Cantioc, la relación edad y género es diferente. En Río Grande vemos a las dos mujeres ubicadas en los polos de la escala, en los grupos de 15 a 19 años y de 60 años y más. Tres hombres, empero, se encuentran distribuidos entre los 25 y 49 años, y el cuarto en 60 y más.

Los datos sobre el estado civil revelan que el suicidio es mucho más frecuente entre hombres casados y mujeres casadas ${ }^{8}$ que entre solteros. De los 34 casos confirmados para Cantioc - no obtuve el dato sobre otros tres-, 19 hombres casados cometieron suicidio frente a cuatro solteros, y nueve mujeres casadas frente a dos solteras. De los seis casos de Río Grande, los cuatro hombres suicidas eran casados; de las dos mujeres, una casada y la otra soltera.

Por convención, los índices de suicidio en la población se miden tomando en cuenta el número de suicidios por cada cien mil personas. Para intentar un acercamiento cuantitativo al fenómeno del suicidio en estas dos localidades, he comparado los datos de 1985 a 2005 de la República mexicana con los de Cantioc y Río Grande, a partir de la información del INEGI sobre población nacional y local. ${ }^{9}$

Para contrastar los datos de población con los de suicidio, fue necesario obtener el promedio de suicidios a nivel nacional para el período $1985-2005 .{ }^{10}$ Con base en los promedios anuales de población - de México, Cantioc y Río Grande - y el promedio nacional de suicidios, las tablas 1 y 2 reflejan la información proveniente de las dos fuentes utilizadas. La tabla 1 recoge los datos de suicidio del Registro Civil y señala que, por cada cien mil habitantes, en Cantioc hay 59.6 muertes y en Río Grande 22.7, mientras que en México son 2.7. La tabla 2 muestra los datos del registro etnográfico, y en éste las cifras de muerte por cien mil habitantes suben: en Cantioc serían 144.8 y en Río Grande 45.5.

La tabla 3 presenta la suma de las dos fuentes disponibles; aclaro que ésta no es la suma simple de dos totales, puesto que varios casos de suicidio aparecen registrados en ambas fuentes y se duplicarían si fueran sumados. Por tanto, la "suma" recoge los casos individuales cotejados a partir del nombre de la víctima, para evitar repeticiones. Así se reportan 157.6 muertes por cien mil habitantes en Cantioc y 45.5 en Río Grande.

Con la intención de contrastar más claramente las diferencias entre los datos provenientes de las dos fuentes, señalo que los aportados por el Registro Civil constituyen para Cantioc el $41 \%$ de los registrados en campo; en el caso de Río Grande, éstos son el 50\% de los del registro etnográfico. La información incluida en esta sección nos alerta sobre las limitaciones de las fuentes oficiales, por el importante subrregistro que presentan, y sobre las dificultades que conlleva construir etnográficamente estos datos. Pero - aun tomando en cuenta estos inconvenientes- se hace palpable que el suicidio ha alcanzado en estas localidades rurales índices inimaginables.

\section{Explicaciones causales locales}

Considero que, desde la perspectiva antropológica, las explicaciones causales locales ofrecen un punto de partida para el análisis del suicidio. Las que expongo a 
continuación provienen de las narrativas de familiares, amigos y vecinos de las víctimas. También incluyo las opiniones de personas que intentaron quitarse la vida sin éxito y de otros que han tenido la ideación suicida sin llevarla a la práctica, así como de varios suicidas que hicieron algunas "confesiones" en las horas de agonía antes de morir.

En la región de estudio, los pobladores atribuyen el suicidio a diferentes causas. ${ }^{\text {.l }}$ Para este artículo retomo las dos explicaciones locales con causalidad social, que imputan este tipo de muerte a ciertas tensiones y contrariedades que resultan de los intercambios cotidianos: los "problemas" y las "envidias". Cuando se habla de "problemas" habitualmente se alude a las dificultades que surgen dentro "de la misma casa", en el interior del grupo doméstico, que es la unidad organizativa más importante en las localidades de estudio. Los casos de suicidio atribuidos a las "envidias" provienen, en cambio, de personas ajenas al grupo doméstico, generalmente vecinos cercanos. En el caso de estas dos explicaciones causales, el suicidio se entiende como una respuesta o salida a los problemas que enfrenta un individuo en relación con otros.

La explicación causal de los problemas apunta a un conjunto de tensiones y negociaciones ríspidas que ocurren en el ámbito doméstico, entre la pareja, por un lado, y entre padres e hijos, por el otro. Llama la atención que no se presentaron casos que se imputaran a conflictos entre hermanos o hermanas. Las tensiones que afectan las relaciones de pareja incluyen el adulterio, tanto de hombres como de mujeres, y se atribuyen suicidios por esta causa al cónyuge del adúltero, pero ocasionalmente también al que cometió la infidelidad. Otro motivo recurrentemente mencionado es el abandono del novio o cónyuge, en este caso, practicado más frecuentemente por los hombres. La violencia de género intradoméstica, muy común en el trato de los hombres hacia sus esposas e hijos, es considerada una causa principal.

En las relaciones intergeneracionales dentro del grupo doméstico, muchos conflictos se desarrollan en torno a la herencia de la tierra, entre el progenitor y los hijos varones. Los hijos, ya casados y con descendencia, reclaman al padre que les entregue la tierra para independizarse. Pero éste dilata la decisión lo más posible para aprovechar la fuerza de trabajo del hijo y la nuera, y detentar su autoridad sobre ellos. Varios casos de suicidio entre hombres jóvenes casados fueron atribuidos a esta circunstancia.

Relacionado con el anterior, igualmente se aduce el suicidio de hijos varones al hecho de que el padre muestra un trato desigual hacia ellos, favoreciendo a algunos por encima de otros - en el reparto de tierras, regalos y comida; al asignar cargas de trabajo; en mostrar simpatía abiertamente- En otro caso se reclama que el padre imponía demasiadas prohibiciones al hijo y que siempre le demostraba desconfianza. Los regaños y ofensas se consideran posibles causales para enfermedades y suicidio.

Pero también se piensa que los hijos pueden orillar a los padres al suicidio por algún acto de desobediencia. Una jovencita entabló noviazgo con un muchacho, sin pedir autorización de sus padres, y se dice que el padre se mató por esta situación. El suicidio de algunos ancianos se ha atribuido a la falta de atención brindada por sus hijos en la vejez, pues los hijos son considerados responsables de esta tarea. Se dio el caso de que un joven golpeó al padre en repetidas ocasiones, y esto supuestamente llevó a que el progenitor se quitara la vida.

Además se mencionan casos en que el suicidio se atribuye a enfermedades largas e incurables, que afectan seriamente al paciente y a su familia en la medida en que no cuentan con recursos suficientes para atenderlas. Igualmente se imputa el suicidio a la discapacidad de algunas personas, que se sienten inhabilitadas para desempeñar sus tareas y llevar una vida "como los demás". En un único caso registrado se atribuyó el suicidio de un hombre mayor al hecho de que su mujer no quería tener relaciones sexuales con él. También se dijo que el suicidio de una jovencita respondió a que estaba embarazada sin estar casada ni comprometida.

En varios casos se planteó que la falta de dinero para cubrir necesidades apremiantes —enfermedades de los hijos o pago de sus estudios, entre otras - fue motivo para que el jefe de familia se quitara la vida. Además se 
señala como causa de suicidio el que las expectativas generadas en torno al matrimonio se vean frustradas por diversos motivos - el novio comprometido abandona a la novia; la joven mujer no puede conseguir marido porque padece alguna discapacidad; la joven que no tiene pretendientes porque sus hermanos son maestros con salarios elevados y los campesinos desisten de cortejarla pues no podrán darle el nivel de vida al que está acostumbrada-.

Cuando se describen los "problemas" asociados al suicidio generalmente se mencionan algunos sentimientos que pudo experimentar la víctima, como la tristeza, el coraje o la desesperación, entre los más frecuentes. Mientras realicé el trabajo de campo, solamente un joven estudiante universitario utilizó el término depresión para referirse al sentimiento que había sentido una mujer por sus problemas maritales y que supuestamente fue la causa de su suicidio.

La segunda explicación causal, la que atribuye el suicidio a la brujería, remite a las "envidias" que surgen entre los pobladores. ${ }^{12}$ En todos los casos recopilados se afirma que dichas envidias siempre se originaron fuera del grupo doméstico. Éstas surgen por "tener un poquito más" o "por estar mejor" que los demás. En las condiciones de pobreza y pobreza extrema de la mayoría de la población, las diferencias se hacen notar en varios aspectos. Por ejemplo, en la posesión de bienes de consumo - casas de cemento y fierro, pequeñas tiendas de abarrotes o ropa, carros para negocio de transportes, aparatos electrodomésticos, mobiliario, ropa y arreglo personal diferentes, entre otros-. También se distinguen aquellos que han adquirido habilidades que son valoradas localmente - estudios de enseñanza media y superior, becas de estudio, plazas de maestros, trabajos asalariados fijos-, así como los que gozan de ciertas capacidades y atributos personales que generan prestigio - belleza, simpatía e inteligencia, tener hijos o cónyuges muy trabajadores-.

\section{Espacio social, posiciones y "estrategias"}

En este apartado me propongo conectar las explicaciones causales locales con los datos antes expuestos de edad, género y estado civil de las víctimas, en el marco del análisis de la dimensión social de las localidades de estudio. El propósito es señalar algunas tendencias en la correlación entre posiciones sociales y vulnerabilidad al suicidio. Diversos antropólogos que han investigado el tema han establecido también correlaciones en el sentido que aquí sugiero. Autores como Spencer (1990) y Counts (1980) han planteado que en las sociedades patriarcales pequeñas son las mujeres, quienes ocupan una posición de subordinación, las que recurren mayoritariamente al suicidio. Esto es así afirman- pues ellas no pueden ventilar sus reclamos públicamente ni esperan cambios en su condición de sometimiento. Niehaus (2012), en cambio, encuentra que en una aldea en Sudáfrica son los hombres - los que ocupan la posición social dominante- quienes cometen más suicidios y no las mujeres. Este último es el caso de las localidades de estudio.

Los "problemas" y las "envidias" que mencionan los pobladores remiten a la dimensión social local, en concreto a las contradicciones inherentes a las relaciones que se dan en dos ámbitos: el grupo doméstico y el espacio social, enmarcados en los procesos de cambio social más amplios. El grupo doméstico ha sido el ámbito tradicional de la organización del trabajo familiar para las actividades agrícolas y domésticas, a la vez que un espacio para la construcción y reproducción/ transformación de relaciones desiguales a partir del género, la edad y el parentesco. Las tensiones intradomésticas son intrínsecas a esta forma de organización social, fundada en la autoridad adulta masculina. Conceptualizado como espacio social, ${ }^{13} \mathrm{en}$ el grupo doméstico los individuos participan de posiciones sociales desiguales - a partir de la edad, el género y el parentesco-, y se relacionan entre sí en condiciones de subordinación o dominación, o en condiciones de relativa igualdad dependiendo de la circunstancia particular. En dicha estructura, los hombres, principalmente el jefe de familia, gozan por lo general de una posición superior a las mujeres - esposa, hijas y nueras—, así como los de mayor edad — adultos y ancianos- ocupan también una posición superior a los jóvenes y niños. Igualmente entre hermanos y 
hermanas se reconoce la diferencia de edad y género, y el hijo varón mayor puede ejercer cierto control sobre los hermanos y hermanas menores. Estas posiciones desiguales de poder juegan un papel importante cuando hay conflictos, pues orientan de alguna manera las respuestas posibles. Sin embargo, las posiciones sociales son cambiantes y es necesario analizarlas en cada situación particular.

En las prácticas cotidianas del grupo doméstico —en torno a la producción agrícola y las tareas del hogar- se dan relaciones de cooperación, pero también surgen los conflictos en torno al manejo y distribución de ciertos bienes, como la tierra y la casa familiar, además de las decisiones sobre el reparto del trabajo y el disfrute de los beneficios de la producción agrícola, entre otros. Dichas prácticas pueden llevar a la reproducción de esta forma de organización social, así como al cuestionamiento del ejercicio de autoridad del jefe de familia en relación con los diferentes miembros del grupo y de otros que detentan igualmente cierto dominio - la suegra frente a la nuera; la madre frente a sus hijos; los hermanos frente a las hermanas, o los hermanos y hermanas mayores frente a los y las menores-. También hay tensiones por los compromisos matrimoniales. Los "problemas" a los que se alude en las narrativas sobre suicidio resaltan que las formas de autoridad y las desigualdades de poder propias de esta forma de organización social no siempre se aceptan pasivamente y que muchas veces los acuerdos establecidos previamente en la práctica son rechazados, cuestionados e impugnados con la intención de negociar y alcanzar otros diferentes. Puede decirse que estas decisiones y acuerdos se revisan permanentemente para los diferentes casos que se presentan (Escalona, 2010).

A las contradicciones propias del grupo doméstico se suma el hecho de que éste ha sufrido transformaciones importantes en la medida en que la agricultura ya no es la fuente principal de subsistencia para los pobladores de estas localidades, ni garantiza siempre la reproducción campesina. El trabajo asalariado, la migración, la educación o el comercio son algunas de las actividades que, desde hace unas cinco décadas, están provocando reacomodos y ajustes en la dinámica de poder doméstica y local, pues han abierto nuevas vías y expectativas para la sobrevivencia no siempre orientada hacia la reproducción social campesina, creando situaciones que producen tensiones intrafamiliares adicionales. La resultante diferenciación socioeconómica ha hecho posible la movilidad social de algunos sectores, que han sacado ventaja de esta circunstancia, aunque no todos han podido acceder a ella. La jerarquía de edad está perdiendo peso sobre la de género. Igualmente ha influido en los cambios el hecho de que las localidades de estudio se encuentren ahora mejor comunicadas por medio de carreteras y terracerías transitables, tienen acceso a la televisión abierta y de paga, a los teléfonos celulares, así como al internet en los pueblos cercanos.

En cuanto a la explicación de las envidias como causal de suicidio, hay que destacar que éstas han formado parte siempre de los intercambios cotidianos, y hacen referencia a las desigualdades socialmente construidas en torno al prestigio y el reconocimiento social en un espacio determinado. ${ }^{14}$ A la vez que expresa estas desigualdades, también es un recurso discursivo para incidir en ellas. ${ }^{15}$ Las circunstancias y aquello que es objeto de envidia han variado con los cambios sociales más generales. Hace unas cuatro décadas, destacaban aquellas prácticas que enaltecían el modo de vida campesino que imperaba en las localidades de estudio; actualmente las envidias giran cada vez más en torno a elementos relacionados con nuevas formas de consumo, trabajo y formas de vida.

A partir de la descripción del funcionamiento de la dinámica social local, a continuación propongo algunas correlaciones entre diversas posiciones sociales - mujeres casadas y solteras, hombres casados y solteros-y la vulnerabilidad que conduce al suicidio. Sin embargo, es importante anticipar que las posiciones sociales de subordinación/dominación o de igualdad no son fijas o estáticas en el tiempo ni en el espacio y se definen de manera relacional en cada circunstancia específica. Por ejemplo, en las localidades de estudio las mujeres ocupan generalmente una posición subordinada en el grupo doméstico, a veces subordinada en extremo. Sin embargo, esta condición de sometimiento no es igual a lo largo de la vida de las mujeres, y su posición puede variar dependiendo de si 
son las mayores o menores, y de si se distinguen por algunas cualidades especiales -inteligencia o belleza, entre otras- Las mujeres casadas y con descendencia generalmente alcanzan una mejor posición que las jóvenes solteras, por ejemplo, y si la mujer practica además otra actividad — curandera, partera, catequista o maestra-, recibe ingresos propios o cuenta con una sólida red familiar de apoyo, esto le permite posicionarse de mejor manera. Porque para determinar la posición social no basta con los referentes del género, la edad y el estado civil, sino que es importante determinar qué está en juego y las posibilidades reales de competir por ello en cada circunstancia específica.

La posición del hombre también cambia a lo largo de su vida. Durante la niñez y hasta el momento en que el padre les cede la tierra, los hombres jóvenes dependen de la autoridad paterna, aunque pueden ejercer cierto control sobre las mujeres de la casa y los hermanos menores. Pero una vez ellos obtienen la tierra y fijan su residencia aparte, la relación con el padre pierde importancia y ellos se desempeñan como autoridad, ahora frente a su esposa, hijos y nueras. La posición del hombre igualmente puede verse modificada si es un proveedor exitoso, desempeña otras actividades económicas, cargos públicos o religiosos, o es curandero o rezador.

Además de que las posiciones sociales no son fijas, es necesario aplicar un enfoque relacional en el caso del comportamiento suicida. Es importante recordar que tanto dentro del grupo de mujeres como del de los hombres se presentan diferencias internas. No todas las mujeres son siempre subalternas ni los hombres siempre dominantes, ${ }^{16}$ y las relaciones de dominación/ subordinación no son siempre iguales, por eso es indispensable analizar la relación específica en cuestión. Por ejemplo, una mujer curandera o maestra puede ocupar una posición superior a un hombre campesino, al enfrentarse a los trámites y funcionarios de la burocracia. Pero en relación con los asuntos ejidales seguramente pesará más la opinión del campesino.

A partir de estas acotaciones con respecto a las posiciones en el espacio social, resumo mi acercamiento analítico de la siguiente manera. En las relaciones conflictivas asociadas al comportamiento suicida en las localidades de estudio, se enfrentan individuos ubicados en posiciones sociales de poder desiguales - y cambiantes-, que actúan de acuerdo con "estrategias" a su alcance para dirimir y desafiar estas diferencias. ${ }^{17}$ Por medio de estrategias, las personas apuestan a obtener mejores acuerdos o condiciones en sus relaciones, es decir, a negociar otras salidas acordes con la situación que buscan y desean vivir. El suicidio, en los casos analizados, describe escenarios en los que la persona no ha podido lograr otros arreglos más favorables y quitarse la vida se presenta como la mejor alternativa. Entiendo el suicidio entonces como la acción "estratégica" de agentes sociales que ocupan posiciones de poder diferenciadas y que buscan cambiar su situación en ese espacio de lucha y competencia por una distribución distinta del poder. En este sentido, coincido con Chua (2009: 239) en que las prácticas suicidas pueden leerse como un "diagnóstico de poder". Es necesario por tanto analizar los casos concretos mediante un acercamiento relacional, como ya se señalaba, pero también histórico, que permita conocer cómo surgieron las posiciones sociales específicas en el espacio social local. Esto apunta necesariamente a entender las profundas relaciones entre las dinámicas locales y las globales. ${ }^{18}$

\section{Mujeres casadas}

La subordinación de las mujeres en las localidades de estudio es innegable; sin embargo, ellas no presentan los índices de suicidio más altos. Si en lugar de tomar únicamente el dato del suicidio a secas enfocamos más bien las relaciones de conflicto y sus causas, veremos que cuando una mujer casada enfrenta los problemas a los que se atribuye localmente el suicidio - violencia, adulterio y abandono-, las respuestas son diversas. Entre éstas se encuentran los intentos fallidos de suicidio -más frecuentes entre mujeres que entre hombres-. Es probable que algunos hayan perseguido la muerte y su intento se viera frustrado por casualidad; pero también se dio el caso de una mujer que reconoció haber tomado "sólo poquito" veneno para escarmentar a su marido pues sospechaba que le era infiel. ${ }^{19}$ 
La mujer víctima de violencia puede encontrar diferentes salidas a su situación: en ocasiones solicita el apoyo de su familia para pedir la intervención de la familia del esposo o para demandarlo ante las autoridades correspondientes. También se dan casos en los que ella abandona temporalmente al marido hasta que éste se comprometa a cambiar su actitud. Se dio el caso de una mujer que aprendió a defenderse a golpes de los abusos del marido, con el apoyo de su hijo adolescente, y de otra que le impedía la entrada a la casa cuando llegaba borracho y agresivo. En otras circunstancias, algunas mujeres abandonadas han ganado juicios que obligan al marido a entregarle una pensión alimenticia que le permita sobrevivir.

Con estos ejemplos quiero mostrar cómo las mujeres tienen cierta capacidad de respuesta ante los conflictos que enfrentan, aún en su condición de subordinación. Ellas pueden "jugar el juego" — de acuerdo con su posición social específica y a las posibilidades reales que les presenta determinada situación - a partir de estrategias que les permitan alcanzar nuevos acuerdos o negociar salidas diferentes. El suicidio es una opción entre la gama de posibles respuestas, aquella que evidencia la renuncia de la mujer a seguir jugando viviendo- seguramente porque su existencia en esas condiciones no tiene ya sentido.

\section{Hombres casados}

Éste es el grupo con mayor incidencia de suicidios. Distingo dentro de éste dos subgrupos a partir de la edad por razones que aclararé más adelante. Los hombres casados enfrentan dos tipos de tensiones: maritales y las relacionadas con su papel de proveedores del grupo doméstico y de autoridad patriarcal. Entre las tensiones maritales están el abandono y adulterio de la mujer. En estas circunstancias, el hombre puede reclamar a la familia de la esposa e incluso hacer intervenir a las autoridades locales; si hay adulterio, es su prerrogativa "regresar" a la mujer o sacarla de la casa y quedarse con algunos de los hijos — si así lo decideSin embargo, estas situaciones dañan la imagen del jefe de familia, pues ponen en evidencia su incapacidad para ejercer la disciplina y el control patriarcal, lo que puede dar pie a burlas y a ridiculización.

Otras disputas provienen de las dificultades que muchos jefes de familia enfrentan actualmente para garantizar la sobrevivencia material de su grupo doméstico. En la mayoría de casos, la producción agrícola no es suficiente y los hombres deben buscar alternativas en la migración, como reorientar su producción agrícola del café al maíz o vender o rentar parte de sus tierras, por ejemplo. Sin embargo, estas alternativas no siempre son fáciles de alcanzar. Como dijo uno de ellos, "somos campesinos... zqué más vamos a hacer?"

El subgrupo de hombres jóvenes casados que ha tenido acceso a la educación y puede desempeñarse en ocupaciones diferentes a la campesina, tampoco tiene garantizado encontrar trabajo en los pueblos o ciudades a los que acuden para emplearse. Además, muchos albergan expectativas sobre su futuro que las generaciones mayores no tuvieron, y que nacen de sus experiencias en la escuela y la migración, y de imágenes de la vida urbana moderna que proyectan los medios de comunicación, principalmente la televisión.

Los jefes de familia de mayor edad también ven cuestionada su autoridad por los hijos e hijas jóvenes en diversos sentidos. Algunos exigen la entrega de sus parcelas, directamente ante el padre o ante las autoridades para dar más fuerza a su exigencia; otros que obtienen ingresos del trabajo asalariado no están dispuestos a acatar las órdenes del padre; muchos establecen noviazgos sin autorización paterna.

En términos generales, a partir de los casos documentados me atrevo - con mucha cautela- a aventurar ciertas explicaciones preliminares. Por un lado, sugiero que muchos de los suicidios entre las mujeres casadas se dan más como respuesta a tensiones intradomésticas, principalmente frente al marido. Estos suicidios podrían interpretarse entonces - habiendo advertido de las dificultades que entrañan las generalizaciones en relación con las posiciones sociales - como una reacción a la condición de dominación que experimentan las mujeres; es decir, como una negativa a seguir viviendo 
en esas condiciones de subordinación. Por otro lado, los suicidios entre los hombres casados remiten a dos fuentes. Así como apuntan a los problemas dentro del grupo doméstico, éstos muestran además cómo los hombres actualmente no siempre están en posibilidad de cumplir con su rol tradicional de proveedores y, por tanto, de ejercer su autoridad como jefes de familia, hechos que pueden conllevar una crisis de masculinidad (Widger, 2009; Arias y Blanco, 2010; Niehaus, 2012). ${ }^{20}$ Los hombres tienen que enfrentar circunstancias adversas relacionadas con los procesos macroeconómicos globales y las repercusiones locales que afectan su reproducción material. Aunada a esta situación están, asimismo, las aspiraciones insatisfechas de muchos jóvenes que albergan la esperanza de una vida diferente a la que tienen.

\section{Mujeres solteras}

Los suicidios de las mujeres solteras son escasos y se dan principalmente por conflictos con la autoridad paterna o por tensiones en las relaciones de noviazgo. A nivel intradoméstico, se ven como la respuesta a los regaños que hacen el padre o la madre por el incumplimiento de las tareas domésticas, por desobediencia o por mantener un noviazgo - y embarazo - fuera de matrimonio. También se habla de maltrato del padre cuando está borracho. Otros suicidios o intentos fallidos se atribuyen a que los padres no cumplieron con las exigencias de dinero o de algún objeto de consumo de la joven.

En cuanto al noviazgo, la tensión puede tener origen en el abandono o ruptura con el novio, el "engaño" en el ofrecimiento de matrimonio o un embarazo sin que el muchacho acepte casarse, por ejemplo. Es importante tener en cuenta que, si los noviazgos son establecidos por los jóvenes por decisión propia, las consecuencias de sus relaciones ya no son imputables a los padres. Al igual que ocurre con las mujeres casadas, puede pensarse que, en una parte, con los suicidios, las solteras buscan romper con su condición de sometimiento a la autoridad paterna. Sin embargo, aquellos relacionados con el noviazgo muestran más bien cómo las jóvenes apostaron por una relación que fracasó, y el suicidio es quizá una forma de no tener que enfrentar otras consecuencias - por ejemplo, no encontrar otro pretendiente o ser madre soltera.

\section{Hombres solteros}

Este grupo concentra pocos casos, pero más que el de las mujeres solteras. Las tensiones que viven los hijos varones solteros se dan en relación con la autoridad paterna, los noviazgos y las nuevas actividades ocupacionales - trabajo remunerado o estudiosque desempeñan fuera del grupo doméstico. Ya he mencionado las disputas con el padre por el reparto de la tierra y las obligaciones de trabajo y disciplina, en el caso de aquellos que continúan buscando la sobrevivencia en la agricultura. También se presentan contrariedades cuando el hijo cuenta con un ingreso salarial, y aunque contribuye al presupuesto doméstico, no está dispuesto a aceptar la autoridad paterna.

Igualmente hay tensiones con los padres por los noviazgos establecidos al margen de la familia. Pero los noviazgos también pueden traer fricciones con la novia; además, el hecho de no tener novia puede dar origen a problemas, pues aunque los jóvenes ya no quieren depender de sus padres para que les encuentren una esposa, muchas veces tienen dificultades para conseguir pareja.

Una fuente de malestar muy grande se desprende también del incumplimiento de expectativas generadas a partir de la educación y de su inserción en los procesos de migración y trabajo asalariado. Algunos han llegado hasta el nivel universitario, pero otros se han quedado en el camino pues no han aprobado los exámenes de ingreso, por ejemplo, o sus familiares no han podido costear esta empresa. Muchos opinan que encontrar trabajo - aun con estudios - ya no está garantizado, y que no tiene sentido hacer el gasto si luego no va a redituar en una alternativa de sobrevivencia.

Entre las mujeres y los hombres solteros, por tanto, podría sugerirse que los conflictos se dan por su condición subordinada dentro del grupo doméstico y por las relaciones de noviazgo. En los hombres solteros, 
las tensiones surgen también por su necesidad de encontrar pareja y formar su propia familia, y por las aspiraciones laborales frustradas.

\section{Reflexión final}

En este artículo me propuse varios objetivos. Por un lado, busqué exponer algunos resultados de mi investigación etnográfica sobre el suicidio, a la vez que intenté mostrar parte del andamiaje que permitió esa construcción. Renuncié a establecer explicaciones causales directas que apuntan a una causa única, directa y clara para cada caso de muerte autoinflingida, porque no me parece un acercamiento viable; en su lugar exploré las correlaciones entre las posiciones sociales - a partir de género, edad y estado civil- y la vulnerabilidad suicida. De esta manera propuse algunas tendencias: aunque las mujeres en general viven en condiciones de fuerte subordinación ante los hombres, y son objeto de violencia en diferentes grados, no son ellas las que presentan los índices más altos de suicidio. No obstante, todo apunta a que la fuente principal del malestar femenino asociado con el suicidio proviene de las circunstancias antes mencionadas. La vulnerabilidad de los hombres se relaciona, por una parte, con los conflictos maritales, pero también, de manera muy importante, con la incapacidad para ejercer la autoridad patriarcal y garantizar el rol de proveedor del grupo doméstico.

Por otro lado, contemplé también un objetivo diferente. Convencida de que una aproximación etnográfica puede coadyuvar al análisis del suicidio, escribí este artículo como una invitación a los antropólogos para realizar más investigaciones sobre el tema. Los altosíndices registrados a nivel local requieren de explicaciones sociológicas y antropológicas, y - como señalé al principio- es urgente discutir y argumentar en torno a los acercamientos teóricometodológicos posibles, destacando sus alcances y limitaciones, así como realizar comparaciones entre estudios de caso diversos. Espero que esta contribución sirva para despertar interés y alentar la discusión sobre la problemática.

\section{Notas}

${ }^{1}$ En este artículo expongo parte de los resultados de una investigación más amplia sobre suicidio. Aquí realizo el análisis de la dimensión social - datos cuantitativos; ejes de análisis en torno al género, edad y estado civil-. La parte que no está incluida trata sobre las concepciones culturales locales (Imberton, 2012a y 2012b).

${ }^{2}$ Realicé esta investigación en dos localidades rurales del municipio de Tila, Chiapas: Río Grande -880 habitantes - y Cantioc - 1426 habitantes - (INEGI, 2010). La población de ambas es mayoritariamente hablante de la lengua chol y, con excepción de algunas mujeres y de los ancianos, también de español. Dedicadas a la agricultura del maíz y frijol para el consumo propio, fueron reconocidas como ejidos en 1934, y a partir de la segunda mitad del siglo XX incorporaron el cultivo del café en pequeña escala. En las últimas décadas las actividades productivas se han diversificado - comercio, oficios, transporte, migración-. Los procesos de cambio apuntan a que el modo de vida campesino está dando paso a novedosos y diversos modos de vida, con expresiones políticas, religiosas y culturales diferentes a las anteriores. En el artículo relaciono algunas de estas transformaciones —en las jerarquías de género y edad, principalmentecon los suicidios.

${ }^{3}$ Una discusión muy completa sobre el tema se encuentra en Douglas (1967).

${ }^{4} \mathrm{~L}$ a ficha que utiliza INEGI contiene catorce indicadores, algunos con respuestas de opción múltiple. Además de los datos puntuales - fecha, lugar y sitio donde ocurrió el acto- y las características personales de la víctima — sexo, edad, religión, estado civil, alfabetismo y escolaridad-, se considera el medio empleado, la causa, la ocupación, la existencia de suicidas en la familia y el número de hijos. También hay una sección para observaciones, así como para el nombre y firma del informante. Las opciones para "causas" son las siguientes: amorosa, dificultad económica, disgusto familiar, enfermedad grave e incurable, enfermedad mental, remordimiento, otra causa -que debe 
especificarse- - y se ignora. Más allá de registrar cierta información, esta ficha refleja una concepción particular sobre la causalidad suicida. Trabajos recientes como el de Chua (2012) muestran cómo las clasificaciones oficiales pueden influir también en la construcción de los entendimientos locales.

${ }^{5}$ La oficina central del Registro Civil de Chiapas se encuentra en Tuxtla Gutiérrez y concentra la documentación de todo el estado, pero no me fue permitido revisar el archivo. Afortunadamente sí tuve a disposición este mismo material en las oficinas de Tila y Petalcingo.

${ }^{6}$ Agradezco a la Mtra. Yasmina López Reyes y a la Lic. Paula Pérez Vázquez su colaboración en la revisión de las actas de defunción del Registro Civil en Tila, Chiapas.

${ }^{7}$ Me fue narrado el caso de un hombre mayor que murió asfixiado y las autoridades ordenaron una autopsia para determinar la causa de muerte. Cuando el cuerpo del occiso regresó a Río Grande, según dicen los familiares, le habían extraído los puentes y coronas de oro de su dentadura.

${ }^{8}$ Bajo el título de casados incluyo a las parejas en unión libre, las casadas por lo civil, a una viuda y a un hombre separado.

9 Aclaro que, debido a la falta de conteos estadísticos para el año de 1985, la población de ese año se estimó tomando en cuenta la media de la tasa de crecimiento de la década en cuestión. Agradezco a la Mtra. Dania Martínez Parente la realización de los cálculos para las siguientes tablas.

${ }^{10}$ Aunque INEGI publica datos anuales, seis de estas cifras - dentro del período en cuestión - no incluyen los casos registrados en el DF, por lo que la información es incompleta. Para sortear esta dificultad, escogí trabajar sólo con cuatro datos quinquenales que sí están completos —1985, 1995, 2000 y 2005- y sacar su promedio. Por esta razón, en las tablas 1, 2 y 3 no se muestra el total de suicidios en México, sino solamente se trabaja con el promedio estimado.

${ }^{11}$ He ordenado las explicaciones causales locales en cuatro grupos, dependiendo de cómo y a quién se atribuye el suicidio: a los problemas cotidianos, a la brujería - motivada por envidias-, a la alcoholización excesiva y al destino divino. La causalidad remite, en unas explicaciones, al orden social y en otras, al sobrenatural. También están imbricadas con las creencias en torno a la conformación de la persona. Para más información, ver Imberton (2012 a y 2012b).

${ }^{12}$ La brujería alude a un conjunto de creencias locales en torno a las entidades anímicas o almas de la persona, relacionadas con la voluntad individual, así como a seres y fuerzas sobrenaturales involucrados en los asuntos humanos (Imberton, 2012a).

13 Parto de la concepción de Pierre Bourdieu (1990) de espacio social como aquél en el que operan ciertos principios de diferenciación constituidos por propiedades particulares que le confieren poder y prestigio al que las posee. Dicho espacio no coincide necesariamente con un espacio físico - la localidad, por ejemplo-, pues sus límites están dados por el alcance de las relaciones que lo conforman y los capitales en disputa - por ejemplo, la tierra y el trabajo-.

${ }^{14}$ Las envidias relacionadas con el suicidio remiten al espacio social local y no al grupo doméstico. Es importante destacar, sin embargo, que en ambos espacios operan los principios diferenciadores de edad y género, por ejemplo, que influyen fuertemente en la dinámica interna. Analíticamente me acerco a ambos con la misma categoría bourdieana de espacio social (Toledo, 2012).

${ }^{15}$ La envidia es un tema recurrente en los estudios antropológicos y existen muchas y diferentes caracterizaciones al respecto. Comparto la de Escalona (2009) y Agudo (2005), que la describen como un "lenguaje de poder" que expresa las desigualdades y los conflictos en un espacio social determinado, a la vez que actúa sobre éstos. Igual interpretación puede darse a las explicaciones causales locales del suicidio, como expresión de tensiones y conflictos y como recurso para incidir en ellos - a manera de acusaciones y contraacusaciones-.

${ }^{16}$ Escalona (2010) y De la Cruz (1999) describen las circunstancias de hombres indígenas tojolabales que no se comportan de acuerdo con el estereotipo de autoridad masculina y que son seriamente 
cuestionados y hasta ridiculizados en su medio. Ver también Arias y Blanco (2010) para el medio rural en América Latina.

${ }^{17}$ Retomo la noción de estrategia de Pierre Bourdieu (1993) que describe cómo los agentes sociales despliegan un sentido práctico o sentido del juego, que se adquiere al participar desde la infancia en las actividades sociales dentro de un espacio histórico y social particular. Éste permite actuar estratégicamente —de manera espontánea- de acuerdo con la posición social del agente en el espacio social más amplio, de las posibilidades reales que les presenta determinada situación y de las ventajas que puedan obtener de ella.

${ }^{18}$ Widger (2009) señala que "como tal, el uso o elección funcional del comportamiento suicida depende no sólo de las diferencias de status entre los individuos en disputa, sino también de la situación de status social adscrita por su ubicación dentro de estructuras de economía política y poder, y de cómo éstas cambian con el tiempo" (traducción de la autora).

${ }^{19}$ Los intentos fallidos de suicidio pueden mejorar o empeorar la condición de subordinación de las mujeres. A veces llevan a un endurecimiento en el trato cotidiano y una mayor vigilancia por parte de la familia política y del marido, y a cierta descalificación de su capacidad como madre y esposa. Chua (2009) registra cómo en una localidad de la India los intentos fallidos muchas veces se tratan médicamente y se somete a la mujer al uso de antidepresivos para "curar" su malestar.

${ }^{20}$ Como ha señalado Bourdieu (2000: 67), la dominación masculina puede revertirse en contra de quienes la despliegan pues "los hombres también están prisioneros y son víctimas subrepticias de la representación dominante".

\section{Referencias bibliográficas}

Agudo Sanchíz, Alejandro, (2005) Unstable Configurations of Power and Difference: the Emergence and Transformation of Leadership and Conflict in the Northern Frontier of Chiapas, Mexico. Tesis de doctorado. Inglaterra, Faculty of Social Sciences and Law, University of Manchester.
Aldous, Joan, Emile Durkheim y Ferdinand Tönnies, (1972) "An Exchange between Durkheim and Tönnies on the Nature of Social Relations, with an Introduction by Joan Aldous, en American Journal of Sociology. Vol. 77, núm. 6, pp. 1191-1200.

Arias, Eliezer e Iraida Blanco, (2010) “Una aproximación al entendimiento del suicidio en comunidades rurales y remotas de América Latina" en Estudios Sociológicos. Vol. XXVIII, núm. 82.

Bohannan, Paul, (1967) "Theories of Homicide and Suicide", en Bohannan, Paul (ed.), African Homicide and Suicide. Nueva York: Atheneum.

Bourdieu, Pierre, (2000) La dominación masculina. Barcelona: Editorial Anagrama.

Bourdieu, Pierre, (1993) Cosas dichas. Barcelona: Gedisa Editorial.

Bourdieu, Pierre, (1990) Sociología y cultura, México: Grijalbo y Conaculta.

Chua, Jocelyn, (2012) "Tales of Decline: Reading Social Pathology in to Individual Suicide in South India", en Culture, Medicine and Psychiatry. Vol. 36, núm. 2. Junio 2012, pp. 204-224.

Chua, Jocelyn Lim, (2009) The Productivity of Death: The Social and Political Life of Suicide in Kerala, South India. Tesis de doctorado. California, Department of Anthropology, Stanford University.

Counts, Dorothy, (1980) "Fighting back is not the way: suicide and the women of Kaliai", en American Ethnologist. Vol. 7, núm. 2. Mayo.

De la Cruz López, Martín, (1999) Hacerse hombres cabales. Prácticas y representaciones de la masculinidad entre indígenas tojolabales de Chiapas. Tesis de maestría. Chiapas, México, CIESAS OccidenteSureste.

Douglas, Jack D., (1967) The Social Meanings of Suicide, Princeton, New Jersey: Princeton University Press.

Durkheim, Emile, (1998) [1897] El suicidio, México: Ediciones Coyoacán.

Escalona Victoria, José Luis, (2009) Política en el Chiapas rural contemporáneo. Una aproximación etnográfica al poder. México: UNAM.

Imberton Deneke, Gracia María, (2012a) Suicidio, entendimientos locales y cambio social entre población chol 
de Chiapas. Tesis de doctorado. México, Programa en Estudios Mesoamericanos, UNAM.

Imberton Deneke, Gracia María, (2012b) "Chol Understandings of Suicide and Human Agency", en Culture, Medicine and Psychiatry. Vol. 36, núm. 2. Junio 2012, pp. 245-246.

INEGI, (2011) Censo general de población y vivienda 2010. Aguascalientes, México: INEGI.

INEGI, (2013) Estadísticas de suicidios de los Estados Unidos Mexicanos 2011. Aguascalientes, México: INEGI.

Johnson, Patricia Lyons, (1981) "When Dying is Better than Living: Female Suicide among the Gainj of Papua Guinea", en Ethnology. Vol. 20, núm. 4, pp. 325-334.

Jones, Gareth, Elsa Herrera y Sarah Thomas de Benítez, (2007) "Tears, Trauma and Suicide: Everyday Violence among Street Youth in Puebla, Mexico", en Bulletin of Latin American Research.Vol. 26, núm. 4, pp. 462-479.

Lisbona Guillén, Miguel, (2005) La comunidad a debate. Reflexiones sobre el concepto de comunidad en el México contemporáneo. México: El Colegio de Michoacán/ Universidad de Ciencias y Artes de Chiapas.

Organización Mundial de la Salud, (2012) "Prevención del suicidio(SUPRE)", en OrganizaciónMental dela Salud. Salud mental [en línea]. S.l., disponible en http://www.who.int/ mental_health/prevention/suicide/suicideprevent/es/ [consultado el 23 de agosto de 2013].
Owens, Christabel y Helen Lambert, (2012) "Mad, Bad or Heroic? Gender, Identity and Accountability in Lay Portrayals of Suicide in Late Twentieth-Century England", en Culture, Medicine, and Psychiatry.Vol. 36, núm. 2. Junio 2012, pp 348-371.

Spencer, Jonathan, (1990) "Collective Violence and Everyday Practice in Sri Lanka", en Modern Asian Studies. Vol. 24, núm. 3, pp. 603-623.

Toledo Tello, Sonia, (2012) De las fincas a las comunidades agrarias: la construcción de los espacios sociales en Simojovel y Huitiupán, Chiapas (siglo XIX-siglo XXI). Tesis de doctorado. México, Programa en Estudios Mesoamericanos-UNAM.

Viqueira, Juan Pedro, (1995) "La comunidad india en México en los estudios antropológicos e históricos", en Anuario 1994. Tuxtla Gutiérrez, Chiapas, CESMECA, Universidad de Ciencias y Artes del Estado de Chiapas.

Widger, Tom, (2012) "Suffering, Frustration, and Anger: Class, Gender and History in Sri Lankan Suicide Stories", en Culture, Medicine, and Psychiatry.Vol. 36, núm. 2. Junio 2012, pp. 225-244.

Widger, Tom, (2009) Self-harm and Self-inflicted Death Amongst Sinhalese Buddhists in Sri Lanka: An Ethnographic Study. Tesis de doctorado. Londres, London School of Economics. 
Tabla 1. Suicidios totales con datos del Registro Civil

\begin{tabular}{|l|r|r|r|}
\hline \multicolumn{1}{|c|}{ Año } & \multicolumn{1}{|c|}{ Cantioc } & \multicolumn{1}{c|}{ Río Grande } & \multicolumn{1}{c|}{ México } \\
\hline Suicidios totales 1985-2005 & 14 & 3 & 2438.25 \\
\hline Promedio anual de suicidios & 0.7 & 0.2 & 89440000 \\
\hline $\begin{array}{l}\text { Promedio de población anual } \\
\text { 1985-2005 }\end{array}$ & 1174 & 660 & 2.7 \\
\hline $\begin{array}{l}\text { Tasa de suicidios base de 100 000 } \\
\text { habitantes }\end{array}$ & 159.6 & 22.7 & \\
\hline
\end{tabular}

Fuente: actas de defunción del Registro Civil. INEGI, censos de población 1980 al 2005. INEGI, estadísticas de intentos de suicidio y suicidios 2003 y 2005.

Tabla 2. Suicidios totales con base en registro etnográfico

\begin{tabular}{|l|r|r|r|}
\hline \multicolumn{1}{|c|}{ Año } & \multicolumn{1}{c|}{ Cantioc } & \multicolumn{1}{c|}{ Río Grande } & México \\
\hline Suicidios totales 1985-2005 & 34 & 0.3 & \\
\hline Promedio anual de suicidios & 1174 & 660 & \\
\hline $\begin{array}{l}\text { Promedio de población anual } \\
\text { 1985-2005 }\end{array}$ & 144.8 & 45.5 & \\
\hline $\begin{array}{l}\text { Tasa de suicidios base de 100 000 } \\
\text { habitantes }\end{array}$ & & & \\
\hline
\end{tabular}

Fuente: datos etnográficos. INEGI, censos de población 1980 al 2005. INEGl, estadísticas de intentos de suicidio y suicidios 2003 y 2005.

Tabla 3. Suicidios totales provenientes de acuerdo con datos del Registro Civil y el registro etnográfico

\begin{tabular}{|l|r|r|r|}
\hline \multicolumn{1}{|c|}{ Año } & Cantioc & \multicolumn{1}{c|}{ Río Grande } & México \\
\hline Suicidios totales 1985-2005 & 37 & -3 & \\
\hline Promedio anual de suicidios & 1.85 & 660 & 2438.25 \\
\hline $\begin{array}{l}\text { Promedio de población anual } \\
\text { 1985-2005 }\end{array}$ & 1174 & 8940000 \\
\hline $\begin{array}{l}\text { Tasa de suicidios base de 100 000 } \\
\text { habitantes }\end{array}$ & 157.6 & 45.5 & 2.7 \\
\hline
\end{tabular}

Fuente: datos etnográficos. INEGI, censos de población 1980 al 2005 . INEGI, estadísticas de intentos de suicidio y suicidios 2003 y 2005. 